\title{
A standardised study to compare prostate cancer targeting efficacy of five radiolabelled bombesin analogues
}

\author{
Rogier P. J. Schroeder • Cristina Müller • Suzanne Reneman • Marleen L. Melis • \\ Wout A. P. Breeman • Erik de Blois • Chris H. Bangma • Eric P. Krenning • \\ Wytske M. van Weerden • Marion de Jong
}

Received: 26 August 2009 / Accepted: 5 January 2010 /Published online: 25 February 2010

(C) The Author(s) 2010. This article is published with open access at Springerlink.com

\begin{abstract}
Purpose Prostate-specific antigen (PSA)-based screening for prostate cancer (PC) has dramatically increased early diagnosis. Current imaging techniques are not optimal to stage early PC adequately. A promising alternative to PC imaging is peptide-based scintigraphy using radiolabelled bombesin (BN) analogues that bind to gastrin-releasing peptide receptors (GRPR) being overexpressed in PC. When labelled to appropriate radionuclides BN targeting of GRPRs may also provide applications for peptide radionuclide receptor therapy (PRRT). Assessment studies under identical experimental conditions allowing a reliable comparison of the potential of such analogues are lacking. This study was performed to evaluate and directly compare five promising radiolabelled $\mathrm{BN}$ analogues for their targeting efficacy for PC under standardised conditions.

Methods The BN agonists $\left[{ }^{111} \mathrm{In}\right]$ DOTA-PESIN, $\left[{ }^{111} \mathrm{In}\right]$ AMBA, $\left[{ }^{111} \mathrm{In}\right] \mathrm{MP} 2346$ and $\left[{ }^{111} \mathrm{In}\right] \mathrm{MP} 2653$ and one antagonist $\left[{ }^{99 \mathrm{~m}} \mathrm{Tc}\right]$ Demobesin-1 were evaluated in GRPR-overexpressing human PC-3 tumour-bearing mice to determine peptide stability in vivo, biodistribution and GRPR targeting potential by animal SPECT/CT imaging and ex vivo autoradiography.

Results HPLC analysis of blood showed intact Demobesin1 at 5 and $15 \mathrm{~min}$ after injection $(64.1 \pm 1.6 \%$ and $41.0 \pm$

R. P. J. Schroeder · C. Müller · M. L. Melis · W. A. P. Breeman ·

E. de Blois $\cdot$ E. P. Krenning $\cdot$ M. de Jong

Department of Nuclear Medicine, Erasmus MC,

Rotterdam, The Netherlands

R. P. J. Schroeder $(\bowtie) \cdot S$. Reneman $\cdot$ C. H. Bangma $\cdot$

W. M. van Weerden

Department of Experimental Urology, Erasmus MC,

Room Be331 (JNI), Dr. Molewaterplein 50,

3015 GE Rotterdam, The Netherlands

e-mail: r.schroeder@hotmail.com

$01 \%$, respectively) being much less for the other compounds. AMBA, the second most stable analogue, showed $36.1 \pm 2.7 \%$ and $9.8 \pm 1.1 \%$ intact peptide after 5 and 15 min. PC-3 tumour uptake at $1 \mathrm{~h}$ was comparable for Demobesin-1, AMBA, PESIN and MP2346 (3.0 $\pm 0.4,2.7 \pm$ $0.5,2.3 \pm 0.5$ and $2.1 \pm 0.9 \% \mathrm{ID} / \mathrm{g}$, respectively), but very low for MP2653 $(0.9 \pm 0.2 \% \mathrm{ID} / \mathrm{g})$. In addition, MP2346 showed undesirably high uptake in the kidneys $(7.9 \pm 1.9 \% \mathrm{ID} / \mathrm{g})$ being significantly less for the other analogues. AMBA, MP2346 and PESIN revealed favourable increases in tumour to blood ratios over time while changes in tumour to kidney and pancreas ratios for Demobesin- 1 from 1 to $24 \mathrm{~h}$ after injection were significantly better than for the other analogues. All analogues visualised PC-3 tumours by SPECT/CT and autoradiography.

Conclusion In the present study the BN antagonist Demobesin-1 was the best performing analogue showing superior in vivo stability, highest tumour uptake and retention while pancreatic and renal clearance were rapid. PESIN and AMBA were the best GRP agonists with sufficient in vivo stabilities as well as high tumour uptake and retention. Based on these results all three analogues deserve further evaluation for clinical use in PC patients.

Keywords Bombesin - Gastrin-releasing peptide receptor . Targeted imaging · Biodistribution · Single positron emission tomography $\cdot$ Radiolabelled analogue $\cdot$ Prostatic neoplasms

\section{Introduction}

Prostate cancer (PC) is the most frequently diagnosed cancer among men in the Western world. It is the third most common cause of death [1]. After its introduction as a biomarker, the prostate-specific antigen (PSA) has been 
increasingly used to detect PC [2] despite its limited diagnostic specificity and prognostic value [3]. The European Randomized Study of Screening for PC (ERSPC) has shown that screening for PC using PSA detection and digital rectal examination has resulted in a fourfold increase in the detection of PC [4]. To select an optimal therapeutic strategy for PC at the time of diagnosis, it is essential to discriminate between organ-confined disease (with local therapy such as surgery or radiation therapy still likely to be beneficial) and PC beyond the confines of the gland (for which a systemic approach such as hormonal therapy is the first choice of treatment). Yet none of the standard imaging modalities are sufficiently reliable in determining the extent of minimal disease at the time of diagnosis [5, 6]. New noninvasive sensitive imaging strategies to accurately diagnose, stage and monitor PC are therefore required. Radiolabelled peptide-based imaging by scintigraphy-single positron emission tomography (SPECT) or positron emission tomography (PET) - may be an interesting alternative to fill this gap and improve diagnostic accuracy for early PC.

Gastrin-releasing peptide receptors (GRPRs) are overexpressed in several primary human tumours and metastases [7]. Using tumour autoradiography, Markwalder and Reubi [8] reported that GRPRs are expressed in invasive prostate carcinomas and in prostatic intraepithelial neoplasms at high density, whereas normal prostate tissue and hyperplastic prostate tissue were predominantly GRPR negative. These findings suggest that GRPR may be used as a molecular basis for diagnosing and staging PC, similar to somatostatin receptors (SST) which are being successfully used in clinical practice [9-12].

Bombesin (BN) and its mammalian counterpart, gastrin-releasing peptide (GRP), bind to the GRPR and are involved in the regulation of a large number of biological processes. Four subtypes of the bombesin receptor are known of which the neuromedin $\mathrm{B}$ receptor $\left(\mathrm{BB}_{1}\right), \mathrm{GRPR}\left(\mathrm{BB}_{2}\right)$ and $\mathrm{BN}$ receptor subtype 3 (BRS-3 or $\mathrm{BB}_{3}$ ) are mammalian receptors and the fourth subtype $\left(\mathrm{BB}_{4}\right)$ is found in amphibians only [7]. The carboxylterminal decapeptide of GRP is similar to that of the 14-amino acid amphibian BN peptide. BN possesses the same biological and immunological activities and also has a high affinity for GRPR. Since BN is assumed to be more stable than GRP, developments have mainly been focused on $\mathrm{BN}$ analogues. BN peptides have been coupled to suitable chelators such as diethylenetriaminepentaacetic acid (DTPA), 1,4,7,10-tetraazacyclododecane- $N, N^{\prime}, N^{\prime \prime}, N^{\prime}$ "-tetraacetic acid (DOTA) and acyclic tetraamine $\left(\mathrm{N}_{4}\right.$, 1,4,8,11-tetraazaundecane functionalised at position 6 for binding to primary amine groups of peptides) to allow labelling with various radionuclides.

DOTA- and DTPA-coupled BN analogues enable high specific labelling with ${ }^{111}$ In because of the superior cellular retention characteristics of this radionuclide [13]. The DOTA chelator can also be labelled with therapeutic radionuclides such as ${ }^{90} \mathrm{Y},{ }^{213} \mathrm{Bi}$ and ${ }^{177} \mathrm{Lu}$, offering the possibility of using these $\mathrm{BN}$ analogues for therapeutic purposes. Additionally, replacement of the DTPA chelator with DOTA allows for radiolabelling with ${ }^{68} \mathrm{Ga}$, making these peptides also suitable for PET imaging [14]. On the other hand, Demobesin-1 with its $\mathrm{N}_{4}$ chelator enables labelling with ${ }^{99 \mathrm{~m}} \mathrm{Tc}$, the most widely used radionuclide in nuclear medicine diagnosis.

The suitability of several radiolabelled $\mathrm{BN}$ analogues for PC targeting has been tested in preclinical and clinical studies (for review see [15]). However, a valid comparison of the potentials of the radiolabelled $\mathrm{BN}$ analogues described in the literature is considerably limited due to different evaluation protocols followed in individual preclinical studies. This situation strongly hampers the selection of the most suitable analogues for further clinical validation. Using GRPR-overexpressing human PC-3 tumour-bearing SCID mice, we evaluated the PC targeting efficacy of five promising radiolabelled $\mathrm{BN}$ analogues for SPECT imaging under identical experimental conditions. With the BN agonists PESIN, AMBA, MP2346 and MP2653 and one antagonist Demobesin-1 [16-20] we performed in vivo stability studies, biodistribution, SPECT/CT imaging and ex vivo autoradiography along with haematoxylin and eosin (H\&E) staining.

\section{Materials and methods}

Analogues and radiolabelling

The tested analogues were selected on the basis of their good PC targeting efficacy, as previously reported. In Fig. 1 I the amino acid compositions of $\mathrm{BN}$ and analogues studied are shown. AMBA [18] and PESIN [20] were kindly provided by Prof. Dr. Mäcke, University Hospital Basel, Switzerland. MP2346 [16] and MP2653 [17] were supplied by BioSynthema (St. Louis, MO, USA). In this study radiolabelling of PESIN, AMBA, MP2346 and MP2653 was performed with ${ }^{111} \mathrm{InCl}_{3}$ (Covedien, Petten, The Netherlands), as described earlier [16, 21-23]. Incubation for the DOTA peptides was performed at $80^{\circ} \mathrm{C}$ for $20 \mathrm{~min}$.

Demobesin-1 was a gift from Dr. T. Maina and Dr. B. Nock, Demokritos, Athens, Greece. This peptide was radiolabelled with ${ }^{99 \mathrm{~m}} \mathrm{Tc}$ as previously described by Nock et al. [19, 23].

In order to prevent oxidation and radiolysis quenchers were added to all radiolabelled analogues. Quenchers used were ascorbate (Bufa BV, Uitgeest, The Netherlands), gentisic acid (Covedien, Petten, The Netherlands) and methionine (Fluka Biochemika, Buchs, Switzerland) [23]. 
I

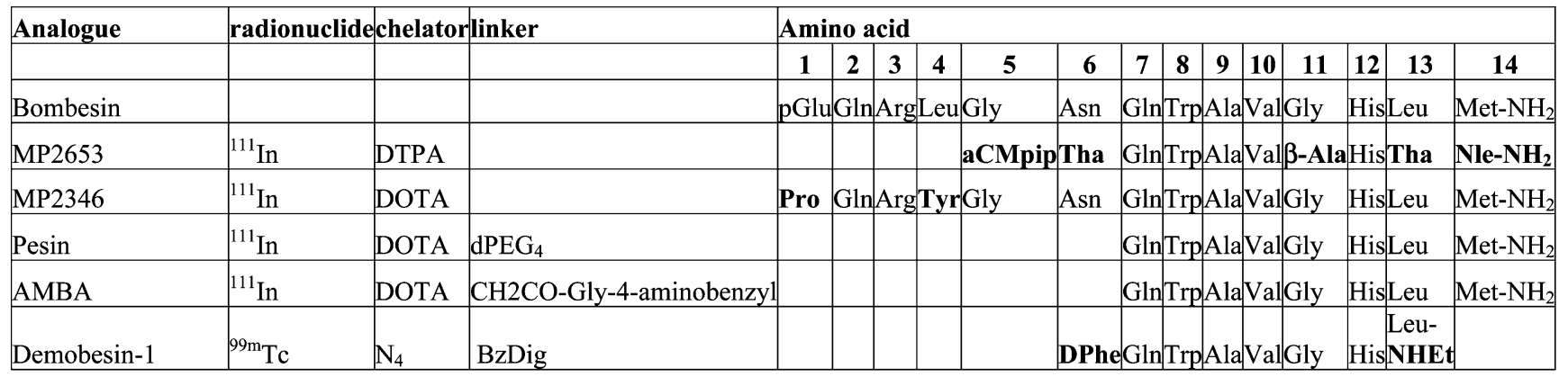

II
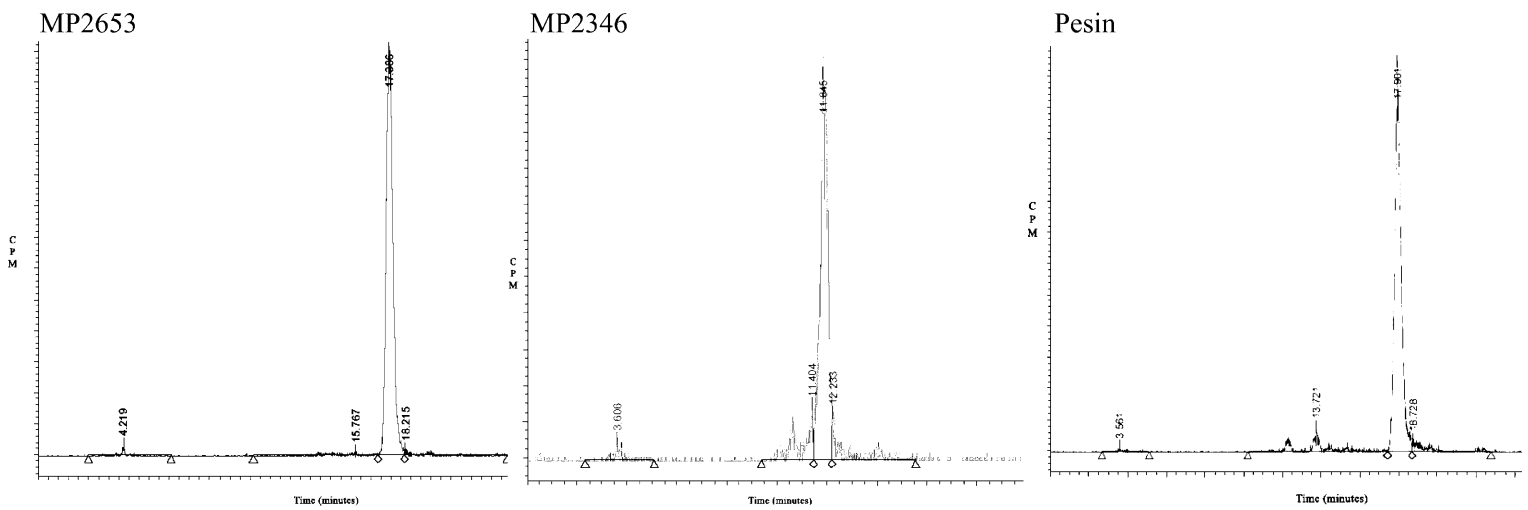

AMBA
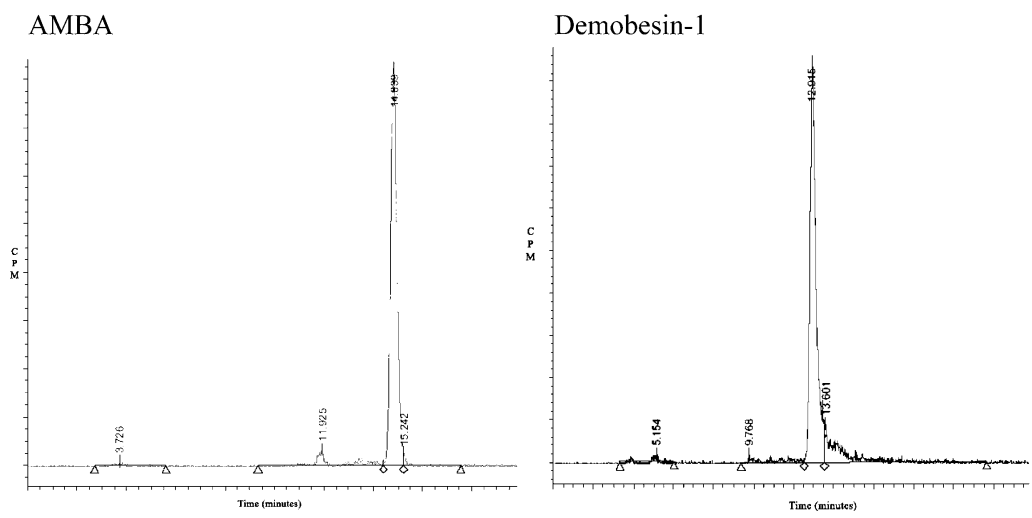

Fig. 1 I Amino acid sequence of native $\mathrm{BN}$ (14 amino acids) and the $\mathrm{BN}$ analogues used in this study. Chelators: $\mathrm{N}_{4}=6-\mathrm{R}-1,4,8,11-$ tetraazaundecane, DOTA $=1,4,7,10$-tetraazacyclododecane-1,4,7,10tetraacetic acid, DTPA = diethylene triamine pentaacetic acid. Linkers: $\mathrm{R}=\mathrm{BzDig}=\mathrm{p}$-aminobenzyldiglycolic acid, $\mathrm{PEG}=$ polyethylene glycol . Introduced amino acids: ACMpip =4-amino-carboxymethylpiperidine

Quality control

The radiolabelling yield and radiochemical purity (RCP) of the labelled analogues were assessed by instant thin-layer chromatography (ITLC) in a 1:1 methanol:ammonium acetate solution [19] and by HPLC (see below). For the ${ }^{99 \mathrm{~m}}$ Tc-labelled analogue Demobesin-1, an extra ITLC with a $100 \%$ acetone solution was performed to quantify ${ }^{99} \mathrm{TcO}_{2}$ content. After radiolabelling and cooling down to ambient temperature, $10 \mu \mathrm{l} 4 \mathrm{mM}$ DTPA was added to the ${ }^{111}$ In-DOTA peptides in order to avoid false-positive (non-natural amino acid), Tha $=\beta$-(2-thienyl)-alanine (non-natural amino acid), $\beta$-Ala $=\beta$-alanine (non-natural amino acid), Nle $=$ norleucine, Pro $=$ proline, $\mathrm{Tyr}=$ tyrosine, Phe $=$ phenylalanine, ${ }^{*}$ reference number from list references. II HPLC of all five radiolabelled analogues $1 \mathrm{~h}$ after labelling

quality control results, e.g. due to colloid formation to complex any free ${ }^{111}$ In [24, 25]. For the yield of incorporation of radioactivity a lower limit of $95 \%$ was set.

HPLC analysis of radiolabelled analogues was performed on a Waters Breeze HPLC system (Waters, Etten-Leur, The Netherlands) based on a 1525 binary HPLC pump connected to a Unispec MCA gamma detector (Canberra, Zellik, Belgium). A Symmetry $\mathrm{C}_{18}$ column (5 $\mu \mathrm{m}, 4.6 \mathrm{~mm} \times$ $250 \mathrm{~mm}$, Waters, Etten-Leur, The Netherlands) served as stationary phase eluted with a solvent system consisting of $0.1 \%$ trifluoroacetic acid (TFA) in $\mathrm{H}_{2} \mathrm{O}$ (solvent $\mathrm{A}$ ) and $0.1 \%$ 
TFA in methanol (solvent B) in a gradient protocol; 0$2 \mathrm{~min} 100 \%$ solvent $\mathrm{A}$ (flow rate $1 \mathrm{ml} / \mathrm{min}$ ), 2-3 $\mathrm{min}$ $55 \%$ solvent $\mathrm{B}, 3-30 \mathrm{~min} 65 \%$ solvent $\mathrm{B}$ (flow rate $0.5 \mathrm{ml} / \mathrm{min}$ ), $30-38 \mathrm{~min} 100 \%$ solvent $\mathrm{B}$ (flow rate $1 \mathrm{ml} /$ min), 38-40 $\min 100 \%$ solvent B and 40-46 min $100 \%$ solvent A.

RCP was estimated for each analogue by evaluating radioactivity peaks eluted from the HPLC column and calculating the area under the curve.

Cell culture

Human PC-3 cells were cultured in RPMI (Lonza, Verviers, Belgium) supplemented with 5\% fetal calf serum (FCS) (GIBCO Invitrogen Co., Grand Island, $\mathrm{NY}$, USA) and $5 \mathrm{ml} / 500 \mathrm{ml}$ penicillin/streptomycin antibiotics $(10,000 \mathrm{IU} / \mathrm{ml}$ penicillin, 10,000 IU/ml streptomycin; Lonza, Verviers, Belgium). Cells were grown in T175 Cellstar tissue culture flasks (Greiner Bio-One $\mathrm{GmbH}$, Frickenhausen, Germany) at $37^{\circ} \mathrm{C}$ in a humidified atmosphere containing $5 \% \mathrm{CO}_{2}$. Cells were passaged using a trypsin-ethylenediaminetetraacetic acid (EDTA) solution (Lonza, Verviers, Belgium), 170,000 IU/1 trypsinversene and $200 \mathrm{mg} / \mathrm{l}$ EDTA. For the present study, cells were grown to near confluency and were than harvested and counted. Suspensions of cells were dissolved in phosphate-buffered saline (PBS) to yield approximately $6 \times 10^{6}$ cells $/ 0.15 \mathrm{ml}$ for subcutaneous injection.

\section{PC-3 xenograft}

Six- to seven-week-old male Swiss $n u / n u$ mice (Charles River, Kißlegg, Germany) were inoculated subcutaneously with PC-3 cells in the right shoulder. A maximum of four mice per cage were kept in $14 \times 13 \times 33.2 \mathrm{~cm}^{3}$ individually ventilated cages (Techniplast), on sawdust (Woody-Clean, type BK8/15; BMI) under a 12-h light-dark cycle, at $50 \pm$ $5 \%$ relative humidity and controlled temperature $\left(\sim 22^{\circ} \mathrm{C}\right)$. Mice received irradiated chow and acidified drinking water ad libitum. Experiments were initiated when the tumour size reached a volume of $200-500 \mathrm{~mm}^{3}$ (3-5 weeks after inoculation).

The experiment was approved by the Animal Experimental Committee (DEC) of the Erasmus $\mathrm{MC}$ and performed in agreement with The Netherlands Experiments on Animals Act (1977) and the European Convention for Protection of Vertebrate Animals Used for Experimental Purposes (Strasbourg, 18 March 1986).

Peptide stability in vivo

Non-tumour-bearing 6- to 7-week-old male Swiss $n u / n u$ mice (Charles River, Kißlegg, Germany) were injected intravenously into a lateral tail vein with $1 \mathrm{nmol}$ radiolabelled analogue labelled with $30 \mathrm{MBq}{ }^{111}$ In or $60 \mathrm{MBq}$

${ }^{99} \mathrm{~m}$ Tc in a volume of $100 \mu \mathrm{l}$. Animals were sacrificed at 5 and $15 \mathrm{~min}$ after administration. For each time point two animals were used.

Blood was collected by orbital puncture in an EDTA tube to prevent clotting and put on ice. Subsequently, samples were centrifuged for $5 \mathrm{~min}, 9,500 \mathrm{~g}$ at $+4^{\circ} \mathrm{C}$, after which the supernatant was collected and precipitated with ethanol (serum:ethanol 1:1). At HPLC run the final ethanol concentration was below 50\%. Precipitated serum was then centrifuged for $5 \mathrm{~min}$ at $9,500 \mathrm{~g}$ to dispose of large proteins. The supernatant containing the radiolabelled peptide was used for HPLC analysis. Results were indicated as percentage of intact radiolabelled peptide as determined from the HPLC analysis (\% intact peptide of two mice per time point).

\section{Biodistribution studies}

PC tumour-bearing mice were injected intravenously into a lateral tail vein with 10 pmol of analogue labelled with an activity of $0.5 \mathrm{MBq}{ }^{111} \mathrm{In}$ or $2.5 \mathrm{MBq}{ }^{99 \mathrm{~m}} \mathrm{Tc}$, in a volume of $0.1 \mathrm{ml}$. Animals were sacrificed at 1,4 or $24 \mathrm{~h}$ after administration of test analogue. For each time point four animals were used. To discriminate between receptorspecific and non-specific binding, for each analogue three additional mice were co-injected with an excess of unlabelled $\left[\mathrm{Tyr}^{4}\right] \mathrm{BN}(0.1 \mathrm{mg}$ in $0.1 \mathrm{ml})$ and sacrificed $4 \mathrm{~h}$ post-injection (p.i.). The tumours and selected tissues (blood, pancreas, kidney and colon) were excised, weighed and counted for radioactivity in a gamma counter (LKB1282-Compugamma system, PerkinElmer, Groningen, The Netherlands). Data were calculated as percentage of the injected dose per gram of tissue $(\% \mathrm{ID} / \mathrm{g})$ using counts from $0.01 \mathrm{ml}$ of the original injectate as reference.

\section{SPECT/CT}

SPECT/CT scans were performed with a four-head multiplexing multi-pinhole NanoSPECT/CT ${ }^{\mathrm{TM}}$ (Bioscan Inc., Washington DC, USA). Each head was equipped with an application-specific tungsten-based collimator with nine pinholes of $1.4 \mathrm{~mm}$ diameter imaging a cylindrical field of view, providing a reconstructed resolution in the submillimetre range. For SPECT/CT a peptide amount of $0.25 \mathrm{nmol}$ in $0.1 \mathrm{ml}$ was injected intravenously. This is needed to enlarge peptide amount for tumour binding to achieve sufficient radioactivity for imaging. Total injected activities ranged from $23-31 \mathrm{MBq}$ for the ${ }^{111}$ In analogues to $142 \mathrm{MBq}$ for Demobesin-1. For each analogue, wholebody scans were performed at 1 and $4 \mathrm{~h}$ after injection of the radiolabelled analogue. An acquisition time of approximately 
$200 \mathrm{~s}$ per view was used, resulting in a total scanning time of about $1 \mathrm{~h} 30 \mathrm{~min}$ per animal. CT scans were performed with the integrated CT using a tube voltage of $45 \mathrm{kV}$ and an exposure time of $1,500 \mathrm{~ms}$ per view. After acquisition, the SPECT data were reconstructed with HiSPECT software (Scivis GmbH, Göttingen, Germany). For CT reconstruction a cone beam filtered backprojection was employed. SPECT and CT data were automatically coregistered since both modalities shared the same axis of rotation. The fused data sets were analysed in the InVivoScope post-processing software (Bioscan Inc., Washington DC, USA). Mice were sacrificed and their tumours were dissected and quickly frozen in liquid nitrogen for subsequent ex vivo autoradiography.

Ex vivo autoradiography

Frozen PC-3 tumours derived from SPECT animals were cut into sections of $10 \mu \mathrm{m}$ (Microm Cryo-Star HM $560 \mathrm{M}$, Walldorf, Germany) and mounted on glass slides (Superfrost plus slides, Menzelgläser, Braunschweig, Germany). Tumour sections were exposed to Super Resolution phosphor imaging screens (Packard Instruments Co., Meriden, CT, USA) in $\mathrm{X}$-ray cassettes. After 24-72 h screens were imaged by a Cyclone phosphor imager and analysed using the OptiQuant 03.00 image processing system (PerkinElmer, Groningen, The Netherlands). After exposure, PC-3 sections were stained with $\mathrm{H} \& \mathrm{E}$ and the staining pattern was compared to the corresponding autoradiogram.

\section{Statistics}

Statistical analyses were performed using SPSS 11.01 (SPSS Inc., Chicago, IL, USA). For this study we applied the Mann-Whitney $U$ test. Statistical significance was assumed if $p$ values were lower than 0.05 .

\section{Results}

Quality control

HPLC radiochromatograms for all analogues are presented in Fig. 1 II. Analyses of ITLC (data not shown) and HPLC indicated a labelling yield for all analogues of more than 97\%. For Demobesin-1, formation of ${ }^{99 \mathrm{~m}} \mathrm{TcO}_{2}$ colloid was $<1 \%$ as concluded from ITLC analysis. RCP ranged from 74 to $93 \%$ for the various peptides.

Peptide stability in vivo

Peptide stability in vivo was highest for Demobesin-1 for both time points. At $5 \mathrm{~min}$ p.i. $64.1 \pm 1.6 \%$ was still intact followed by AMBA (36.1 $\pm 2.7 \%)$, PESIN (23.3 $\pm 1.4 \%$ ), MP2346 (21.2 $\pm 0.8 \%)$ and MP2653 (9.8 $\pm 0.5 \%)$. At $15 \mathrm{~min}$ p.i. still $41.03 \pm 0.11 \%$ of intact Demobesin- 1 could be recovered with lower recoveries for AMBA $(9.8 \pm 1.1 \%)$, MP2346 (3.4 $\pm 1.3 \%)$, MP2653 $(2.8 \pm 0.4 \%)$ and PESIN $(1.8 \pm 0.6 \%)$ (Table 1$)$. As derived from dose calibrator measurements of activities in supernatant and serum it could be concluded that over $90 \%$ of total activity had been extracted from the serum after the precipitation procedure (data not shown).

\section{Biodistribution studies}

Uptake results in various tissues for all radiolabelled analogues at all time points are summarised in Table 2 . Figure 2 shows a graph of the tumour uptake results for all analogues at all time points. The highest PC-3 tumour uptake was obtained with Demobesin-1 $(3.0 \pm 0.4 \% \mathrm{ID} / \mathrm{g})$ at $1 \mathrm{~h}$ p.i. The analogues AMBA, PESIN, MP2346, and MP2653 showed lower tumour uptakes at this time point: $2.7 \pm 0.5,2.3 \pm 0.5,2.1 \pm 0.9$ and $0.9 \pm 0.2 \% \mathrm{ID} / \mathrm{g}$, respectively. The differences in tumour uptake at $4 \mathrm{~h}$ p.i. were consistent with those at $1 \mathrm{~h}$. At $24 \mathrm{~h}$, tumour retention of the ${ }^{111} \mathrm{In}$-DOTA analogues AMBA and PESIN was highest: $1.6 \pm 0.4$ and $1.2 \pm 0.2 \% \mathrm{ID} / \mathrm{g}$, respectively, with lower outcomes for MP2346, Demobesin-1 and MP2653 $(0.7 \pm 0.4,0.4 \pm 0.1$ and $0.4 \pm 0.1 \% \mathrm{ID} / \mathrm{g}$, respectively). ${ }^{99 \mathrm{~m}} \mathrm{Tc}$-labelled Demobesin- 1 showed the most substantial decline in tumour uptake of 7.1-fold from 1 to $24 \mathrm{~h}$, unlike what was observed for the other peptides. Tumour uptake of MP2653 was significantly lower than that of the other analogues at all time points.

AMBA showed the highest uptake in the GRPRexpressing pancreas at $1 \mathrm{~h}$ p.i. $(40.9 \pm 3.3 \% \mathrm{ID} / \mathrm{g})$. Lower uptake was found for Demobesin-1, PESIN, MP2653 and MP2346 (23.8 $\pm 3.2,20.8 \pm 3.9,14.7 \pm 3.8$ and $9.0 \pm 2.5 \% \mathrm{ID} / \mathrm{g}$, respectively). Demobesin-1 showed a considerable washout from pancreas resulting in a 25 -fold increase in tumour to pancreas ratio from 1 to $24 \mathrm{~h}$ p.i. Increase in the tumour to pancreas ratio over time was significantly less for MP2653, PESIN, AMBA and MP2346: 2.7-, 1.0-, 0.7- and 0.5-fold, respectively (Fig. 3a).

In addition to the pancreas, also GRPR-specific uptake of radiolabel in colon was observed. Receptor specificity of peptide uptake was confirmed by co-injecting an excess of unlabelled $\left[\mathrm{Tyr}^{4}\right] \mathrm{BN}$ resulting in strongly reduced uptake $(>80 \%)$ of radiolabel in the colon. PC-3 tumours and GRPR-expressing pancreas showed a comparable blocking pattern for all analogues indicating GRPR-specific uptake. Colon uptake was highest for AMBA as compared to other analogues at all time points: $6.8 \pm 0.9$ versus $2.9 \pm 1.5,2.5 \pm 1.2,2.5 \pm 0.4$ and $2.1 \pm 0.4 \%$ $\mathrm{ID} / \mathrm{g}$ at $1 \mathrm{~h}$ p.i. for PESIN, Demobesin-1, MP2653 and MP2346, respectively (Table 1). 
Table 1 In vivo stability of all analogues at 5 and $15 \mathrm{~min}$ p.i. injecting $1 \mathrm{nmol}$ of radiolabelled analogue $\left(30 \mathrm{MBq}{ }^{111}\right.$ In or 60 $\left.\mathrm{MBq}{ }^{99 \mathrm{~m}} \mathrm{Tc}\right)$ i.v. in a volume of $0.1 \mathrm{ml}$ in non-tumour-bearing nude mice. Results are indicated as $\%$ intact analogue from total injected analogue per mouse

\begin{tabular}{lllll}
\hline Analogue & $\begin{array}{l}\text { Mean (5 min) } \\
\text { Mouse 1 }\end{array}$ & Mouse 2 & $\begin{array}{l}\text { Mean (15 min) } \\
\text { Mouse 1 }\end{array}$ & Mouse 2 \\
\hline$\left[{ }^{99 \mathrm{~m}} \mathrm{Tc}\right]$ Demobesin-1 & 62.9 & 65.2 & 41,0 & 41.1 \\
{$\left[{ }^{111} \mathrm{In}\right]$ AMBA } & 34.2 & 38.0 & 9,0 & 10.6 \\
{$\left[{ }^{111} \mathrm{In}\right]$ PESIN } & 24.4 & 22.4 & 1.4 & 2.3 \\
{$\left[{ }^{111} \mathrm{In}\right]$ MP2346 } & 21,8 & 20.6 & 4.3 & 2.4 \\
{$\left[{ }^{111} \mathrm{In}\right]$ MP2653 } & 10.2 & 9.5 & 2.6 & 3.1 \\
\hline
\end{tabular}

The uptake of radiolabel by the kidneys was significantly higher for MP2346 (7.9 $\pm 1.9 \% \mathrm{ID} / \mathrm{g}$ at $1 \mathrm{~h})$ as compared to the other analogues at all time points: $3.6 \pm 0.7,3.2 \pm 1.2,2.7 \pm 1.0$ and $2.0 \pm 0.3 \% \mathrm{ID} / \mathrm{g}$ at $1 \mathrm{~h}$ for AMBA, Demobesin-1, PESIN and MP2653, respectively (Table 1). The change in tumour to kidney ratio from 1 to $24 \mathrm{~h}$ p.i. was significantly higher for Demobesin-1 as compared to the other analogues: 3.6-fold versus 2.1-, 1.8-, 1.8- and 1.0-fold for PESIN, AMBA, MP2653 and MP2346, respectively (Fig. 3b).

All peptides, except for MP2653 and Demobesin-1, showed high tumour to blood ratios indicating fast clearance from circulation. PESIN showed the largest increase in tumour to blood ratio of 14.4-fold from 1 to $4 \mathrm{~h}$ followed by MP2346 and AMBA (5.7 and 5.5, respectively) with the lowest ratios for MP2653 and Demobesin-1 (3.5 and 2.6, respectively) (Fig. 3c).

SPECT/CT and ex vivo autoradiography

All analogues were able to image subcutaneous PC-3 tumours by SPECT/CT at 1 and $4 \mathrm{~h}$ p.i. (Fig. $4 \mathrm{I}$ ).
Additionally, ex vivo autoradiography of PC-3 tumours was performed at 1 and $4 \mathrm{~h}$ p.i. Autoradiography revealed considerable heterogeneity of peptide binding within the tumour for all analogues with reduced binding in some (central) areas of the tumour as was also observed by in vivo SPECT/CT imaging. H\&E staining of consecutive slides revealed that this heterogeneous expression pattern coincided with reduced cell density in these tumour areas (Fig. 4 II).

\section{Discussion}

In order to initiate BN-based scintigraphic (SPECT) patient studies for the imaging of early $\mathrm{PC}$, we reviewed preclinical studies from the literature as well as our own studies in search of a promising $\mathrm{BN}$ analogue. Due to the lack of standardisation of experiments performed by various research groups, finding consistent comparisons-and thus a reliable choice of candidates - for further clinical validation was very difficult. For this reason, we decided to set up
Table 2 Biodistribution data of all five radiolabelled analogues at time points $\mathrm{A}, \mathrm{B}$ and $\mathrm{C}$ in PC-3 tumour-bearing athymic nude mice injected with $10 \mathrm{pmol}$ peptide, labelled with an activity of $0.5 \mathrm{MBq}{ }^{111}$ In or $2.5 \mathrm{MBq}$ ${ }^{99 \mathrm{~m}} \mathrm{Tc}$, in a volume of $0.1 \mathrm{ml}$ into a lateral tail vein. Results are the mean and standard deviation of four mice per analogue per time point

\begin{tabular}{lccccc}
\hline Organ & {$\left[{ }^{111} \mathrm{In}\right] \mathrm{MP} 2653$} & {$\left[{ }^{111} \mathrm{In}\right] \mathrm{MP} 2346$} & $\left.{ }^{111} \mathrm{In}\right] \mathrm{PESIN}$ & {$\left[{ }^{111} \mathrm{In}\right] \mathrm{AMBA}$} & {$\left[{ }^{99 \mathrm{~m}} \mathrm{Tc}\right] \mathrm{Demobesin}-1$} \\
\hline A. 1 h p.i. $(\% \mathrm{ID} / \mathrm{g} \pm \mathrm{SD})$ & & & & \\
Blood & $0.2 \pm 0.1$ & $0.4 \pm 0.5$ & $0.3 \pm 0.1$ & $0.2 \pm 0.0$ & $0.6 \pm 0.1$ \\
Pancreas & $14.7 \pm 3.8$ & $9.0 \pm 2.5$ & $20.8 \pm 3.9$ & $40.9 \pm 3.3$ & $23.8 \pm 3.2$ \\
Kidneys & $2.0 \pm 0.3$ & $7.9 \pm 1.9$ & $2.7 \pm 1.0$ & $3.6 \pm 0.7$ & $3.2 \pm 1.2$ \\
Colon & $2.5 \pm 0.4$ & $2.1 \pm 0.4$ & $2.9 \pm 1.5$ & $6.8 \pm 0.9$ & $2.5 \pm 1.2$ \\
Tumour & $0.9 \pm 0.2$ & $2.1 \pm 0.9$ & $2.3 \pm 0.5$ & $2.7 \pm 0.5$ & $3.0 \pm 0.4$ \\
B. 4 h p.i. (\%ID/g $\pm \mathrm{SD})$ & & & & \\
Blood & $0.0 \pm 0.0$ & $0.0 \pm 0.0$ & $0.0 \pm 0.0$ & $0.0 \pm 0.0$ & $0.2 \pm 0.0$ \\
Pancreas & $11.4 \pm 2.5$ & $8.9 \pm 2.1$ & $17.5 \pm 2.8$ & $40.5 \pm 7.6$ & $4.1 \pm 1.6$ \\
Kidneys & $1.2 \pm 0.4$ & $10.6 \pm 1.6$ & $1.5 \pm 0.4$ & $3.4 \pm 1.4$ & $1.1 \pm 0.2$ \\
Colon & $1.6 \pm 0.6$ & $1.8 \pm 0.7$ & $3.6 \pm 0.4$ & $5.6 \pm 1.2$ & $1.2 \pm 0.3$ \\
Tumour & $0.7 \pm 0.2$ & $1.4 \pm 0.4$ & $1.6 \pm 0.2$ & $1.9 \pm 0.3$ & $2.2 \pm 0.4$ \\
C. 24 h p.i. $(\% \mathrm{ID} / \mathrm{g} \pm \mathrm{SD})$ & & & & \\
Blood & $0.0 \pm 0.0$ & $0.0 \pm 0.0$ & $0.0 \pm 0.0$ & $0.0 \pm 0.0$ & $0.0 \pm 0.0$ \\
Pancreas & $2.4 \pm 0.7$ & $5.8 \pm 1.4$ & $14.5 \pm 2.8$ & $32.9 \pm 5.2$ & $0.1 \pm 0.0$ \\
Kidneys & $0.6 \pm 0.3$ & $2.8 \pm 0.9$ & $0.7 \pm 0.4$ & $1.3 \pm 0.5$ & $0.1 \pm 0.0$ \\
Colon & $0.8 \pm 0.2$ & $0.6 \pm 0.3$ & $1.0 \pm 0.4$ & $3.2 \pm 0.8$ & $0.1 \pm 0.1$ \\
Tumour & $0.4 \pm 0.1$ & $0.7 \pm 0.4$ & $1.2 \pm 0.2$ & $1.6 \pm 0.4$ & $0.4 \pm 0.1$ \\
\hline
\end{tabular}




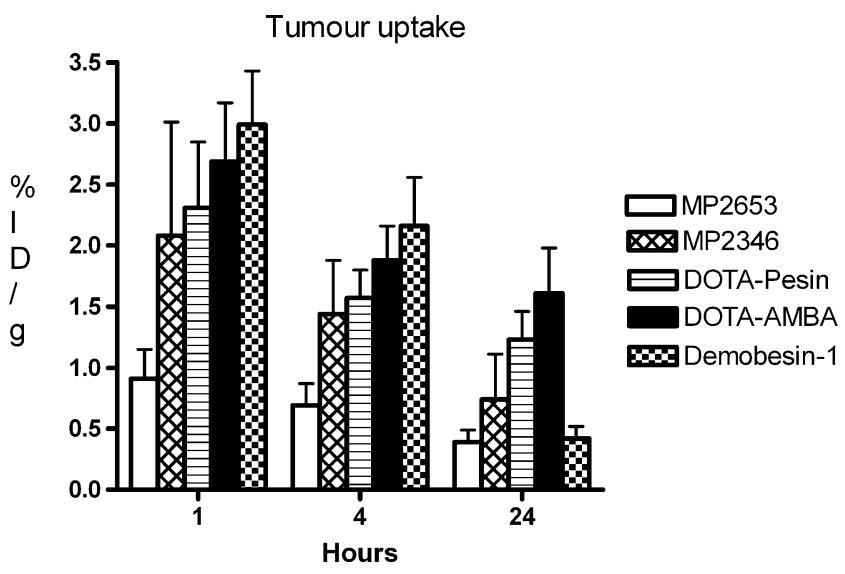

Fig. 2 Tumour uptake for all analogues in PC-3 tumour-bearing athymic nude mice injected with $0.5 \mathrm{MBq}{ }^{111} \mathrm{In}$ or $2.5 \mathrm{MBq}{ }^{99 \mathrm{~m}} \mathrm{Tc}$ bound to $10 \mathrm{pmol}$ of peptide conjugate, in a volume of $0.1 \mathrm{ml}$ into a lateral tail vein sacrificed at 1,4 and $24 \mathrm{~h}$ p.i. Results are indicated as mean \pm standard deviation of four mice per analogue per time point

a comparative study using a number of BN analogues under identical experimental conditions. Five radiolabelled analogues that had already been shown to have good GRPR affinities and targeting characteristics were selected for this

a. tumour-pancreas

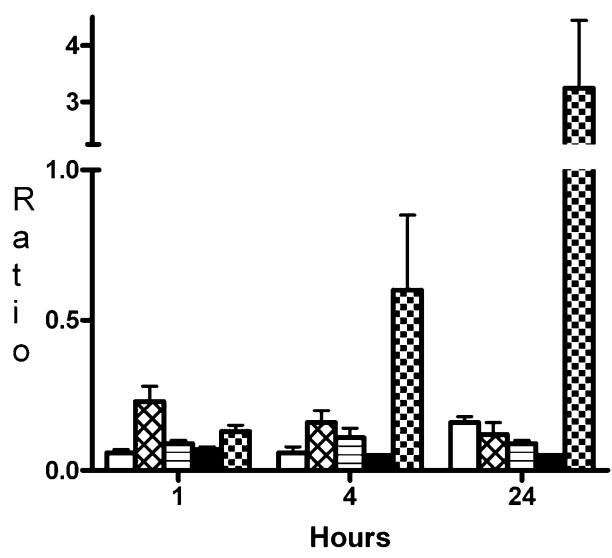

$\square \mathrm{MP} 2653$

खणMP2346

קDOTA-Pesin DOTA-amba ExDemobesin-1

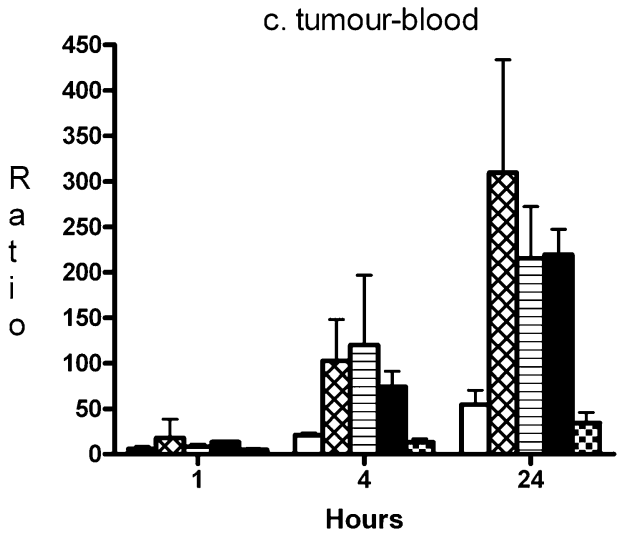

Fig. 3 Ratios calculated from biodistribution in PC-3 tumour-bearing athymic nude mice injected with $0.5 \mathrm{MBq}{ }^{111} \mathrm{In}$ or $2.5 \mathrm{MBq}{ }^{99 \mathrm{~m}} \mathrm{Tc}$ bound to $10 \mathrm{pmol}$ of peptide conjugate, in a volume of $0.1 \mathrm{ml}$ into a study. Four of the radiolabelled BN analogues were GRPR agonists (AMBA, PESIN, MP2653 and MP2346) and one was an antagonist (Demobesin-1) [16-20].

The choice for the BN agonist PESIN was based on studies that reported PC-3 tumour uptake of PESIN labelled with ${ }^{67} \mathrm{Ga}$ of $14.8 \% \mathrm{ID} / \mathrm{g} 1 \mathrm{~h}$ after injection [20]. In another study, PC-3 tumour uptake of AMBA labelled with ${ }^{177} \mathrm{Lu}$ at $1 \mathrm{~h}$ p.i. was $6.4 \% \mathrm{ID} / \mathrm{g}$ [18]. This analogue has already been applied in a therapeutic clinical study [26]. MP2346 [16] and MP2653 [17] labelled with ${ }^{111}$ In have also shown high affinity for GRPR. All agonists were labelled with ${ }^{111}$ In via DTPA or DOTA.

The antagonist Demobesin-1 was included because of its very good profile (tumour uptake $1 \mathrm{~h}$ p.i. of $16.2 \% \mathrm{ID} / \mathrm{g}$ in PC-3 tumour-bearing mice) shown in a preclinical study by Nock et al. [19]. Furthermore, recent preclinical studies using SST analogues suggest that radiolabelled antagonists are superior to agonists with regard to tumour uptake and retention of radioactivity [27]. Although it was shown that the antagonists did not trigger receptor internalisation in SST receptor-expressing cells - a feature that was previously thought to be a crucial characteristic for good retention of

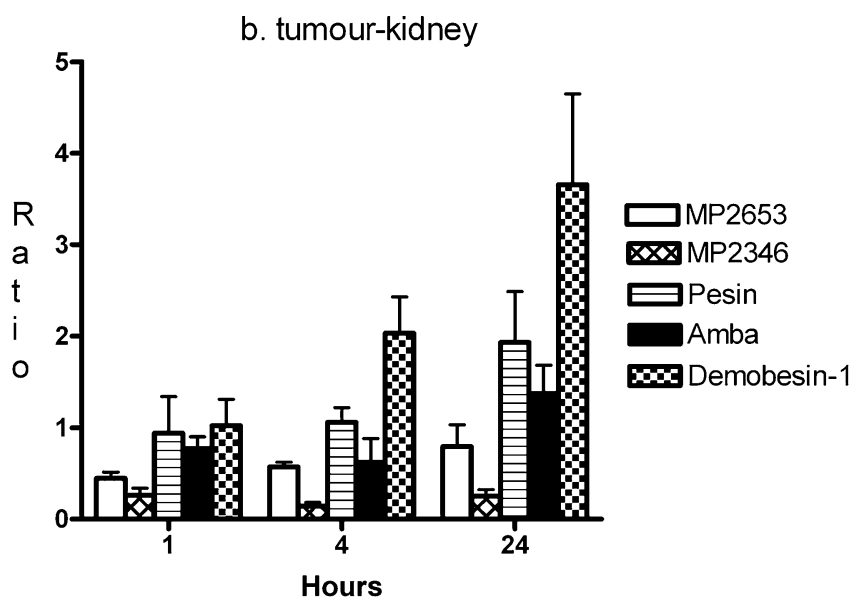

lateral tail vein sacrificed at 1,4 and $24 \mathrm{~h}$ p.i. Data show the tumour to blood ratio (a), tumour to pancreas ratio (b) and tumour to kidney ratio (c) at all time points for all radiolabelled analogues 
Fig. 4 I SPECT/CT image of the $\mathrm{PC}-3$ tumour in athymic xenografts at $1 \mathrm{~h}$ after i.v. tail injection of $0.25 \mathrm{nmol}$ of radiolabelled analogue (23-31 MBq for ${ }^{111} \mathrm{In}$ and $142 \mathrm{MBq}$ for ${ }^{99 \mathrm{~m}} \mathrm{Tc}$ ) in a volume of $0.1 \mathrm{ml}$ into a lateral tail vein. a AMBA, b Demobesin-1, c MP2653, d PESIN, e MP2346. II Autoradiograms (right) and corresponding H\&E-stained sections (left) of a PC-3 tumour derived from a mouse $4 \mathrm{~h}$ after injection of MP2346 (a) and AMBA (b). Ex vivo tumour sections were derived from PC-3 tumour-bearing athymic nude mice injected with $0.25 \mathrm{pmol}$ peptide, labelled with 23$31 \mathrm{MBq}$ for ${ }^{111} \mathrm{In}$ analogues in a volume of $0.1 \mathrm{ml}$ into a lateral tail vein
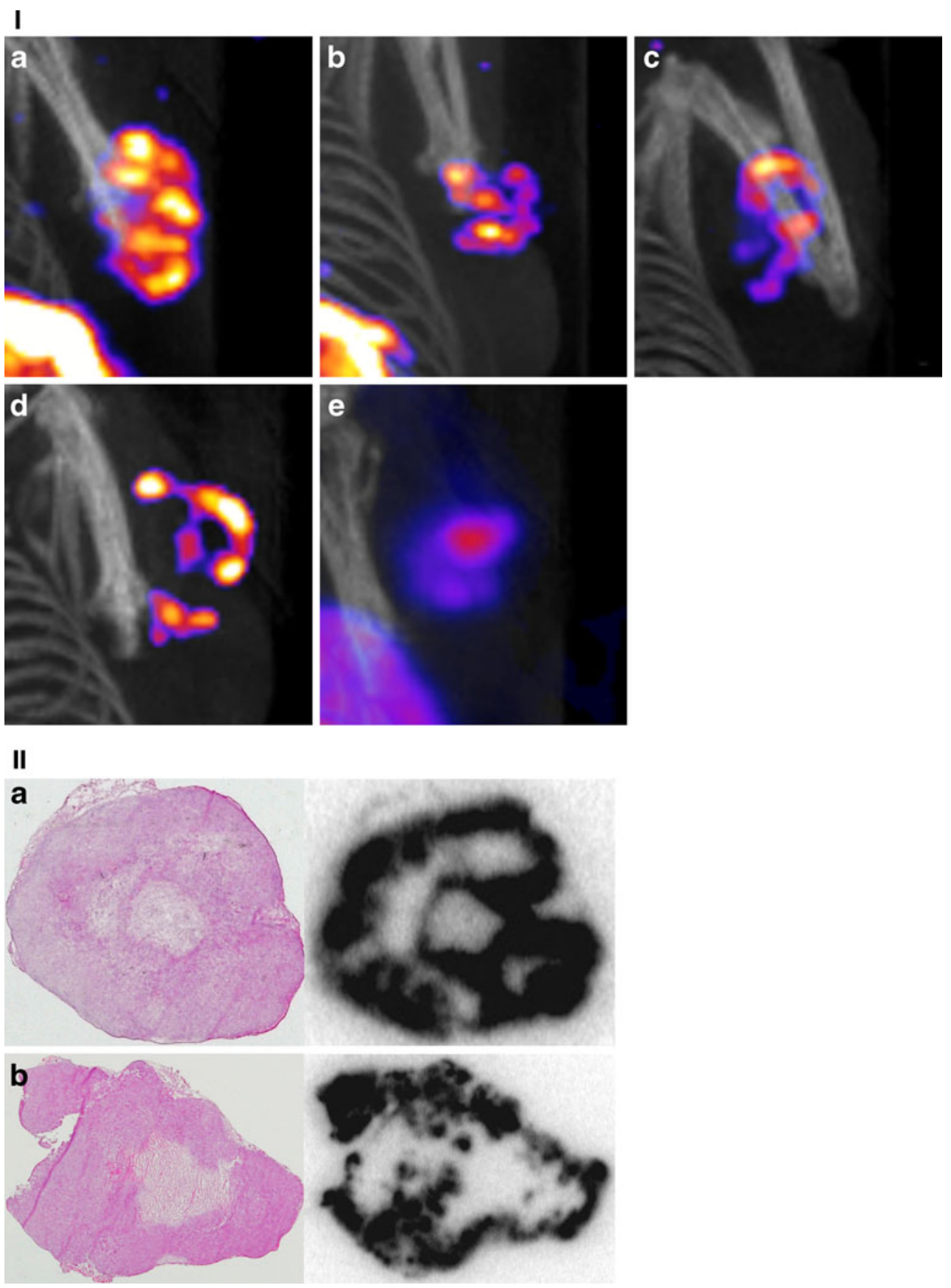

tumour radioactivity - tumour values were reported to be higher for the antagonist than for the agonist. Also, the antagonists were shown washed out from normal organs much faster than agonists, which would potentially result in a reduction in radiotoxicity of normal organs. Recently, GRPRbased PC-3 tumour targeting using Demobesin-1 was also shown to be superior to an agonistic $\mathrm{BN}$ analogue with comparable receptor affinity [28].

The differences in half-life between the radionuclides we used required the inclusion of both early and late evaluation time points (1, 4 and $24 \mathrm{~h}$ p.i.). This enabled us to evaluate tissue and blood retention rates of the analogues over time.
In the biodistribution studies we used 10 pmol of peptide per animal for all analogues. The peptide mass selected was based on the amounts reported in the literature [19, 20]. Also it was chosen while the peptide mass enables an appropriate labelling yield for biodistribution for all analogues [19, 20].

In the present study Demobesin-1 showed the highest tumour uptake at 1 and $4 \mathrm{~h}$ p.i., although these values were not statistically significantly different from those of AMBA, PESIN and MP2346. Tumour uptake of MP2653 was significantly lower when compared with that of all other analogues at all time points. Since sufficient tumour 
uptake is a prerequisite for diagnostic and therapeutic use, MP2653 was excluded from further evaluation. Although MP2346 showed good tumour uptake, it had an unfavourable and significantly higher uptake in the kidney when compared with the other analogues at all time points. This high renal uptake strongly limits its clinical use because of potential nephrotoxicity during peptide radionuclide receptor therapy (PRRT). For this reason, MP2346 was not further considered as best clinical analogue.

In contrast to the reduction in tumour uptake of Demobesin-1 from $3.0 \pm 0.4 \% \mathrm{ID} / \mathrm{g}$ at $1 \mathrm{~h}$ to $0.4 \pm 0.1 \% \mathrm{ID} / \mathrm{g}$ at $24 \mathrm{~h}$ p.i., tumour retention of radioactivity after AMBA and PESIN injection remained fairly stable over this time period, indicating that these two analogues have potential for imaging at later time points. Also, this characteristic may be well suited for PRRT when BN analogues are coupled to therapeutic radionuclides for PRRT. Since a DOTA chelator allows AMBA and PESIN to bind a wide variety of radionuclides, both conjugates are suitable for imaging and PRRT purposes. Research on labelling $\mathrm{N}_{4}$ chelated analogues with the beta-emitting ${ }^{188} \mathrm{Re}$ is ongoing.

The pancreas is the organ with the highest GRPR expression in mice. Its (non-intended) peptide uptake in relation to the targeted tumour uptake is of concern when evaluating GRPR targeted peptides. The tumour to pancreas ratio of Demobesin-1 showed an impressive and significant 4.6-fold increase from 1 to $4 \mathrm{~h}$, which was much less marked in the other analogues (0.7-fold in AMBA and 1.2fold in PESIN). In accordance with the study of Cescato et al. [28], the BN antagonist Demobesin-1 was rapidly washed out from the GRPR-expressing pancreas, while tumour uptake remained relatively high resulting in 25-fold higher tumour to pancreas ratios. We also observed this phenomenon in a patient study where we administered Demobesin-1 and compared it with an agonist ${ }^{111}$ In-[DTPA$\mathrm{Pro}^{1}, \mathrm{Tyr}^{4}$ ]bombesin (unpublished data).

Besides uptake of radioactivity in the pancreas, GRPRspecific uptake - as could be concluded from in blocking data - by the colon was also observed. Colon uptake is also highly relevant to PC imaging as it may interfere with detection of PC metastatic lesions at abdominal sites. Furthermore, it may induce colon radiotoxicity when employed for PRRT. Unfavourable GRPR-specific colon uptake was twofold higher for AMBA than for the other peptides.

Ideally, the tumour to blood ratios of analogues should increase over time with high retention in the tumour and declining activity in the circulation. Both AMBA and PESIN analogues showed large increases in tumour to blood ratios from 1 to $4 \mathrm{~h}$ (5.5-fold and 14.1-fold, respectively). In contrast, Demobesin-1 showed the smallest change in this ratio (a 2.7-fold change between 1 and $4 \mathrm{~h}$ ). The slower clearance of Demobesin-1 from the blood resulting in a lower tumour to blood ratio in comparison with the DOTA-chelated peptides may be related to the fact that the agonists are more hydrophilic and are therefore rapidly cleared by the kidney, whereas the lipophilic Demobesin-1 is excreted by the hepatobiliary tract as well. This could influence clearance kinetics. Rapid conversion to hydrophilic metabolites may also accelerate blood clearance of the agonists. Despite its favourable high tumour to blood ratio, the very high renal uptake of MP2346 remains a major disadvantage of this peptide.

Generally, peptides for use in peptide receptor targeted scintigraphy or therapy are chosen for their good BN receptor-targeting characteristics and in vitro stability. The in vitro serum half-life data of the BN peptides used in this study ranged from $3 \mathrm{~h}$ to several days $[17-19,21]$. Peptide stability of analogues in vivo is, however, of much more relevance. For this reason, in the present study we determined the in vivo peptide stability of all analogues using HPLC. Peptide stability in vivo of all four agonists was very similar. Demobesin-1 was the most stable analogue. We can however not completely exclude the presence of unknown radiolabelled metabolites besides the intact peptide in the main peaks from HPLC. Despite the significantly longer in vivo peptide stability of Demobesin-1, tumour uptakes for this analogue were not significantly different from those of AMBA and PESIN. This implies that interactions between GRPR and BN occur rapidly. There was no direct correlation between in vivo peptide stability and analogue performance in mice.

The administration of pharmacologically active agonistic peptides is known to cause endocrine and haemodynamic effects by the process of endocytosis [29]. Antagonists on the other hand do not have the potential to enter and activate cells and, as a consequence, pharmacological side effects may be less. This is especially relevant for PRRT where higher amounts of peptide are used than for imaging studies. Furthermore, several experimental studies have shown that $\mathrm{BN}$ antagonists induce anti-tumour effects [3034], while BN agonists generally stimulate PC tumour growth $[7,35,36]$. Another advantage of Demobesin-1 is that it is highly selective for GRPR and has no affinity for other BN receptor subtypes, NMB-R and BB3-R [19]. The agonists AMBA and PESIN are not selective and bind to both GRPR and NMB-R [18, 20].

With regard to absolute tumour uptake of radioactivity, the present study showed lower tissue uptakes than is described for these analogues in the literature. The variation in radionuclides, amounts of peptide, mouse strain (species, sex, weight), PC-3 tumour cells (passage number, culture conditions) used, tumour size and vascularisation of the tumour may all be factors that determine uptake of radioactivity resulting in variable outcomes. This further underlines the necessity to evaluate and compare such analogues under standardised conditions. 
The present study showed that all analogues were able to target subcutaneous PC- 3 tumours as visualised by SPECT/ CT. Ex vivo autoradiography of PC-3 tumours further revealed that in all analogues there was considerable heterogeneity in the distribution of radioactivity between individual tumours. The heterogenic pattern could be histologically related to areas with reduced cell density, predominantly in the centre of the tumours. This was further supported by the SPECT/CT images showing a rimlike tumour image. When considering using radiolabelled BN for PRRT, it should be taken into account that the area that will be irradiated contains all vital PC cells. Mouse models are not ideal while central necrosis results in underestimation of uptake $(\% \mathrm{ID} / \mathrm{g})$. This underlines the necessity to perform biodistribution on mice with small tumours only. Furthermore, it should be investigated whether central necrosis occurs in patient tumours as well.

In conclusion, the comparison of five analogues performed in the present study provides a realistic reflection of the potential of a number of peptides, in spite of the differences between tumour uptake and normal organ values found in our experiments and those of previous studies. The BN antagonist Demobesin-1 showed the highest tumour uptake 1 and $4 \mathrm{~h}$ p.i., with a particularly good tumour to pancreas ratio and a significantly higher in vivo analogue stability compared with the other analogues. This good performance, in combination with the advantages of the use of antagonists over agonists and its ${ }^{99 \mathrm{~m}} \mathrm{Tc}$ label, make Demobesin-1 a very attractive analogue for PC imaging. Based on high tumour uptake, retention profiles and good tumour to blood ratios combined with sufficient stability in vivo, PESIN and AMBA outperformed the other two agonists. As they have a DOTA chelator, both analogues are currently more easily applicable for PRRT than the $\mathrm{N}_{4}$-functionalised Demobesin-1 analogue. Our results indicate that all three $\mathrm{BN}$ analogues deserve further evaluation for clinical nuclear imaging, and possibly PRRT, of human PC. Demobesin-1 has been selected for a first proof of concept clinical study.

Acknowledgements We are grateful to the Dutch Cancer Society for their financial support (Grant Number: 12977368).

Open Access This article is distributed under the terms of the Creative Commons Attribution Noncommercial License which permits any noncommercial use, distribution, and reproduction in any medium, provided the original author(s) and source are credited.

\section{References}

1. Jemal A, Siegel R, Ward E, Hao Y, Xu J, Murray T, et al. Cancer statistics, 2008. CA Cancer J Clin 2008;58:71-96.
2. Stamey TA, Yang N, Hay AR, McNeal JE, Freiha FS, Redwine E. Prostate-specific antigen as a serum marker for adenocarcinoma of the prostate. N Engl J Med 1987;317:909-16.

3. Thompson IM, Pauler DK, Goodman PJ, Tangen CM, Lucia MS, Parnes HL, et al. Prevalence of prostate cancer among men with a prostate-specific antigen level $<$ or $=4.0 \mathrm{ng}$ per milliliter. N Engl J Med 2004;350:2239-46.

4. Schröder FH, Denis LJ, Roobol M, Nelen V, Auvinen A, Tammela $\mathrm{T}$, et al. The story of the European Randomized Study of Screening for Prostate Cancer. BJU Int 2003;92 Suppl $2: 1-13$.

5. el-Gabry EA, Halpern EJ, Strup SE, Gomella LG. Imaging prostate cancer: current and future applications. Oncology (Williston Park) 2001;15:325-36; discussion 339-42.

6. Hricak H, Schöder H, Pucar D, Lis E, Eberhardt SC, Onyebuchi $\mathrm{CN}$, et al. Advances in imaging in the postoperative patient with a rising prostate-specific antigen level. Semin Oncol 2003;30:61634.

7. Jensen RT, Battey JF, Spindel ER, Benya RV. International Union of Pharmacology. LXVIII. Mammalian bombesin receptors: nomenclature, distribution, pharmacology, signaling, and functions in normal and disease states. Pharmacol Rev 2008;60:1-42.

8. Markwalder R, Reubi JC. Gastrin-releasing peptide receptors in the human prostate: relation to neoplastic transformation. Cancer Res 1999;59:1152-9.

9. Krenning EP, Teunissen JJ, Valkema R, deHerder WW, deJong M, Kwekkeboom DJ. Molecular radiotherapy with somatostatin analogs for (neuro-)endocrine tumors. J Endocrinol Invest 2005;28:146-50.

10. Krenning EP, Kwekkeboom DJ, Bakker WH, Breeman WA, Kooij PP, Oei HY, et al. Somatostatin receptor scintigraphy with [111In-DTPA-D-Phe1]- and [123I-Tyr3]-octreotide: the Rotterdam experience with more than 1000 patients. Eur J Nucl Med 1993;20:716-31.

11. Kwekkeboom D, Krenning EP, de Jong M. Peptide receptor imaging and therapy. J Nucl Med 2000;41:1704-13.

12. Valkema R, De Jong M, Bakker WH, Breeman WA, Kooij PP, Lugtenburg PJ, et al. Phase I study of peptide receptor radionuclide therapy with [In-DTPA] octreotide: the Rotterdam experience. Semin Nucl Med 2002;32:110-22.

13. Duncan JR, Stephenson MT, Wu HP, Anderson CJ. Indium-111diethylenetriaminepentaacetic acid-octreotide is delivered in vivo to pancreatic, tumor cell, renal, and hepatocyte lysosomes. Cancer Res 1997;57:659-71.

14. Maina T, Nock B, Mather S. Targeting prostate cancer with radiolabelled bombesins. Cancer Imaging 2006;6:153-7.

15. Schroeder RP, van Weerden WM, Bangma C, Krenning EP, de Jong M. Peptide receptor imaging of prostate cancer with radiolabelled bombesin analogues. Methods 2009;48:200-4.

16. Biddlecombe GB, Rogers BE, de Visser M, Parry JJ, de Jong $\mathrm{M}$, Erion JL, et al. Molecular imaging of gastrin-releasing peptide receptor-positive tumors in mice using $64 \mathrm{Cu}-$ and $86 \mathrm{Y}-$ DOTA-(Pro1,Tyr4)-bombesin(1-14). Bioconjug Chem 2007; 18:724-30.

17. de Visser M, Bernard HF, Erion JL, Schmidt MA, Srinivasan A, Waser B, et al. Novel 111In-labelled bombesin analogues for molecular imaging of prostate tumours. Eur J Nucl Med Mol Imaging 2007;34:1228-38.

18. Lantry LE, Cappelletti E, Maddalena ME, Fox JS, Feng W, Chen $\mathrm{J}$, et al. 177Lu-AMBA: synthesis and characterization of a selective 177Lu-labeled GRP-R agonist for systemic radiotherapy of prostate cancer. J Nucl Med 2006;47:1144-52.

19. Nock B, Nikolopoulou A, Chiotellis E, Loudos G, Maintas D, Reubi JC, et al. [99mTc]Demobesin-1, a novel potent bombesin 
analogue for GRP receptor-targeted tumour imaging. Eur J Nucl Med Mol Imaging 2003;30:247-58.

20. Zhang H, Schuhmacher J, Waser B, Wild D, Eisenhut M, Reubi JC, et al. DOTA-PESIN, a DOTA-conjugated bombesin derivative designed for the imaging and targeted radionuclide treatment of bombesin receptor-positive tumours. Eur J Nucl Med Mol Imaging 2007;34:1198-208.

21. Breeman WA, de Jong M, Erion JL, Bugaj JE, Srinivasan A, Bernard BF, et al. Preclinical comparison of (111)In-labeled DTPA- or DOTA-bombesin analogs for receptor-targeted scintigraphy and radionuclide therapy. J Nucl Med 2002;43:1650-6.

22. Breeman WA, De Jong M, Visser TJ, Erion JL, Krenning EP. Optimising conditions for radiolabelling of DOTA-peptides with 90Y, 111In and 177Lu at high specific activities. Eur J Nucl Med Mol Imaging 2003;30:917-20.

23. Breeman WA, Fröberg AC, de Blois E, van Gameren A, Melis M, de Jong M, et al. Optimised labeling, preclinical and initial clinical aspects of CCK-2 receptor-targeting with 3 radiolabeled peptides. Nucl Med Biol 2008;35:839-49.

24. Breeman WA, Kwekkeboom DJ, de Blois E, de Jong M, Visser TJ, Krenning EP. Radiolabelled regulatory peptides for imaging and therapy. Anticancer Agents Med Chem 2007;7:345-57.

25. Liu S, Edwards DS, Harris AR, Ziegler MC, Poirier MJ, Ewels BA, et al. Towards developing a non-SnCl2 formulation for RP444, a new radiopharmaceutical for thrombus imaging. J Pharm Sci 2001;90:114-23.

26. Bodei LFM, Nunn J, Llull J, Cremonesi M, Martano L, Laurora G, Scardino E, Tiberini S, Bufi G, Eaton S, de Cobelli O, Paganelli O 177Lu-AMBA Bombesin analogue in hormone refractory prostate cancer patients: a phase I escalation study with single-cycle administrations. European Association of Nuclear Medicine 2007; abstract 463 .

27. Ginj M, Zhang H, Waser B, Cescato R, Wild D, Wang X, et al. Radiolabeled somatostatin receptor antagonists are preferable to agonists for in vivo peptide receptor targeting of tumors. Proc Natl Acad Sci U S A 2006;103:16436-41.
28. Cescato R, Maina T, Nock B, Nikolopoulou A, Charalambidis $\mathrm{D}$, Piccand $\mathrm{V}$, et al. Bombesin receptor antagonists may be preferable to agonists for tumor targeting. J Nucl Med 2008;49:318-26.

29. Koenig JA, Edwardson JM. Endocytosis and recycling of $G$ protein-coupled receptors. Trends Pharmacol Sci 1997;18:276-87.

30. Jungwirth A, Pinski J, Galvan G, Halmos G, Szepeshazi K, Cai $\mathrm{RZ}$, et al. Inhibition of growth of androgen-independent DU-145 prostate cancer in vivo by luteinising hormone-releasing hormone antagonist Cetrorelix and bombesin antagonists RC-3940-II and RC-3950-II. Eur J Cancer 1997;33:1141-8.

31. Milovanovic SR, Radulovic S, Groot K, Schally AV. Inhibition of growth of PC-82 human prostate cancer line xenografts in nude mice by bombesin antagonist RC-3095 or combination of agonist [D-Trp6]-luteinizing hormone-releasing hormone and somatostatin analog RC-160. Prostate 1992;20:269-80.

32. Pinski J, Schally AV, Halmos G, Szepeshazi K. Effect of somatostatin analog $\mathrm{RC}-160$ and bombesin/gastrin releasing peptide antagonist RC-3095 on growth of PC-3 human prostatecancer xenografts in nude mice. Int J Cancer 1993;55:963-7.

33. Plonowski A, Schally AV, Varga JL, Rekasi Z, Hebert F, Halmos $\mathrm{G}$, et al. Potentiation of the inhibitory effect of growth hormonereleasing hormone antagonists on PC-3 human prostate cancer by bombesin antagonists indicative of interference with both IGF and EGF pathways. Prostate 2000;44:172-80.

34. Stangelberger A, Schally AV, Varga JL, Zarandi M, Szepeshazi K, Armatis P, et al. Inhibitory effect of antagonists of bombesin and growth hormone-releasing hormone on orthotopic and intraosseous growth and invasiveness of PC-3 human prostate cancer in nude mice. Clin Cancer Res 2005;11:49-57.

35. Jensen JA, Carroll RE, Benya RV. The case for gastrin-releasing peptide acting as a morphogen when it and its receptor are aberrantly expressed in cancer. Peptides 2001;22:689-99.

36. Schally AV, Comaru-Schally AM, Plonowski A, Nagy A, Halmos G, Rekasi Z. Peptide analogs in the therapy of prostate cancer. Prostate 2000;45:158-66. 